\title{
O efeito das exportações no crescimento econômico das microrregiões brasileiras: uma análise espacial com dados em painel *
}

\author{
Alex Sander Souza do Carmo \\ Professor - Universidade Estadual de Ponta Grossa (UEPG) \\ Endereço: Rua Cel. Bitencourt, 689 - Centro - Ponta Grossa-PR \\ CEP: 84010-290 - E-mail: acarmo@uepg.br
}

\begin{abstract}
Augusta Pelinski Raiher
Professora - Universidade Estadual de Ponta Grossa (UEPG)

Endereço: Rua Cel. Bitencourt, 689 - Centro - Ponta Grossa-PR

CEP: 84010-290 - E-mail: apelinski@gmail.com
\end{abstract}

\author{
Alysson Luiz Stege \\ Professor - Universidade Estadual de Ponta Grossa (UEPG) \\ Endereço: Rua Cel. Bitencourt, 689 - Centro - Ponta Grossa-PR \\ CEP: 84010-290 - E-mail: alyssonstege@gmail.com
}

Recebido: 10/09/2015. Aceite 27/10/2016.

\begin{abstract}
Resumo
O objetivo do presente trabalho é analisar empiricamente os efeitos das exportações sobre o crescimento econômico das microrregiões brasileiras durante o período de 20002010, à luz do modelo de Feder (1982). Conforme o referido modelo, as exportações aumentam o crescimento econômico por meio do diferencial de produtividade existente entre o setor exportador e não exportador, bem como pela externalidade positiva gerada pelo setor exportador sobre o setor não exportador. Estimando o modelo empírico pela técnica de painel de dados espacial, com efeito fixo, as duas hipóteses centrais do modelo de Feder (1982) foram corroboradas, evidenciando-se que as exportações têm efeitos indiretos sobre o crescimento econômico das microrregiões brasileiras.
\end{abstract}

\section{Palavras-Chave}

Crescimento. Exportações. Microrregiões.

\begin{abstract}
The aim of this study is to analyze the effects of exports on the economic growth of Brazilian micro-regions, during the period 2000-2010, in the light of Feder model (1982). According to Feder model, exports increases economic growth because of productivity difference existing between the export sector and the non-exporter sector and because of the positive externality generated by the export sector on the non-export sector. Estimating the empirical model by the technique of spatial panel data, with fixed effect, the
\end{abstract}

- Este artigo faz parte do projeto "O efeito das exportações no crescimento econômico das microrregiões do Brasil: uma análise espacial com dados em painel”, financiado pelo Conselho Nacional de Desenvolvimento Científico e Tecnológico (CNPq). 
assumptions of the Feder model were confirmed, showing that exports have indirect effects on economic growth of the Brazilians micro-regions.

\section{Keywords}

Growth. Exports. Micro-regions.

\section{JEL Classification}

O40.

\section{Introdução}

O crescimento econômico é essencial para que os países em desenvolvimento consigam convergir para níveis de bem-estar próximos ao das economias avançadas. Ademais, sua fomentação contribui para a obtenção de outros objetivos, como a geração de empregos e a melhor distribuição de renda e riqueza.

A partir do seminal artigo de Solow (1956), o tema "crescimento econômico" (doravante crescimento) recebeu atenção da literatura, tanto teórica quanto empírica, em que os pesquisadores procuraram responder perguntas como: o que determina o crescimento econômico dos países? ou, ainda, por que os países crescem a taxas distintas? $\mathrm{Na}$ extensa literatura sobre o assunto, um grande número de trabalhos objetivou analisar o papel das exportações em tal processo; e é particularmente neste campo da pesquisa que o presente estudo se enquadra.

Balassa (1978) apontou que os efeitos positivos das exportações no crescimento dos países ocorrem por dois caminhos: um direto e outro indireto. $\mathrm{O}$ efeito direto ocorre porque as exportações integram a demanda agregada e, naturalmente, um aumento nas exportações promoverá uma elevação do Produto Interno Bruto (PIB) do país. Já o efeito indireto (que também é denominado de efeito dinâmico) ocorre porque uma maior abertura ao comércio internacional irá potencializar a eficiência produtiva, resultado do melhor aproveitamento das economias de escala e de melhor alocação dos recursos na economia. 
Para captar os efeitos diretos e indiretos das exportações sobre o crescimento, duas especificações de modelos se sobressaem na literatura empírica: uma baseada no modelo de Solow (1956) e outra no modelo de Feder (1982). Quando a especificação do modelo empírico deriva do modelo de Solow (1956), a estratégia dos pesquisadores é inserir, dentre as variáveis explicativas, uma variável que denota as exportações; dessa forma, o coeficiente associado a essa variável fornecerá o efeito direto das exportações no crescimento econômico. Uma séria limitação dessa abordagem é que o modelo econométrico não permite identificar a magnitude dos efeitos indiretos das exportações sobre o crescimento. $\mathrm{Na}$ tentativa de superar tal problema, outra abordagem ganhou destaque na literatura aplicada, derivada do modelo teórico de Feder (1982). Nele, a economia é dividida em dois setores, um exportador e outro não exportador. Ambos os setores possuem como fatores de produção o capital e o trabalho, sendo que o setor não exportador, além desses dois fatores, também produz em função do setor exportador. O efeito do setor exportador sobre o setor doméstico ocorre porque existe um diferencial de produtividade entre os setores e, ainda, existe uma externalidade (spillover) do setor exportador no setor não exportador. Partindo disso, a abordagem derivada do modelo de Feder (1982) permite captar os efeitos indiretos das exportações no crescimento.

Considerando tal contexto, o presente trabalho tem como objetivo estimar os efeitos das exportações sobre o crescimento econômico das microrregiões do Brasil no período compreendido entre 2000 a 2010, à luz do modelo de Feder (1982). A escolha desse modelo como fundamentação teórica se justifica pela tentativa de captar os efeitos indiretos das exportações no crescimento econômico das microrregiões. Em termos metodológicos, devido à natureza dos dados utilizados, que são espaciais, o modelo econométrico será estimado por meio do método de dados em painel espacial.

Vale aqui destacar que a maior parte dos trabalhos aplicados estima os efeitos das exportações no crescimento, considerando os dados de países, ao passo que o presente estudo utiliza os dados das microrregiões brasileiras. A utilização dos dados microrregionais tem por objetivo levar em consideração as heterogeneidades locais na discussão acerca dos efeitos do comércio internacional no crescimento, sendo que essa discussão é de suma importância para o desempenho econômico das microrregiões brasileiras (PEROBELLI; HADDAD, 
2006). Estes autores argumentam que trabalhar com dados locacionais permite identificar dois efeitos espaciais: a dependência espacial e a heterogeneidade espacial. A dependência espacial ocorre devido à presença das aglomerações espaciais, fazendo com que os dados geográficos não sejam independentes entre si; essa dependência espacial é denominada como autocorrelação espacial. Já o conceito de heterogeneidade espacial ocorre porque cada região possui características intrínsecas que as tornam únicas; por conta disso, é possível identificar diferentes padrões espaciais das exportações, bem como no crescimento econômico.

A escolha das microrregiões do Brasil como recorte geográfico, em vez dos municípios, partiu do argumento defendido por Breitbach (2008). Para esse autor, o uso das microrregióes como espaço de análise fornece um grau de aproximação mais adequado das relações econômicas e sociais que caracterizam o "meio local", entendido como um espaço suficientemente pequeno, em que a proximidade entre os agentes favorece a criação de sinergias capazes de manter em funcionamento um sistema econômico localizado.

Outro ponto importante a ser considerado é que, como a variável em estudo é a exportação, muitas vezes a produção pode ser feita em municípios periféricos, mas a empresa exportadora pode se localizar no município polo, nele registrando o valor exportado. Por conta disso, os dados referentes aos municípios podem superestimar ou subestimar o verdadeiro valor da exportação do município, prejudicando os resultados da análise. Por outro lado, com o recorte microrregional, esse efeito tende a ser mitigado.

Além da presente introdução, o artigo possui outras quatro seções. Na seção 2, descreve-se, sucintamente, o modelo teórico de Feder (1982) e apresentam-se alguns trabalhos empíricos que avaliaram os efeitos das exportações no crescimento econômico à luz desse modelo. Na seção 3 , discorre-se a respeito da metodologia que será empregada no presente estudo, enfocando tanto na construção do modelo empírico quanto na estratégia de estimação dos parâmetros. Na seção 4, realiza-se uma análise exploratória dos dados espaciais e se discute os resultados obtidos nas estimações do modelo empírico. Findando o trabalho, a seção 5 reporta às considerações finais. 


\section{Referencial teórico e revisão de literatura}

\subsection{O modelo de Feder}

Como mencionado na introdução, o presente estudo pretende investigar o efeito das exportações no crescimento econômico das microrregiões brasileiras à luz do modelo de Feder (1982). Assim, descreve-se sucintamente o referido modelo.

Feder (1982) divide a economia em dois setores: um exportador e outro não exportador. A produção do setor exportador $(X)$ é em função dos fatores de produção capital $\left(K_{x}\right)$ e trabalho $\left(L_{x}\right)$, ao passo que a produção do setor não exportador $(N)$ é em função dos fatores de produção capital $\left(K_{n}\right)$ e trabalho $\left(L_{n}\right)$, bem como da produção do setor exportador $(X)$, ou seja:

$$
\begin{aligned}
& X=G\left(K_{x}, L_{x}\right) \\
& N=F\left(K_{n}, L_{n}, X\right)
\end{aligned}
$$

Derivando-se parcialmente as funções $X$ e $N$ em relação ao capital e ao trabalho, e dividindo as produtividades marginais dos fatores de produção do setor exportador pelas suas respectivas produtividades marginais dos fatores de produção do setor não exportador, obtém-se:

$$
\left(\frac{\mathrm{G}_{\mathrm{K}}}{\mathrm{F}_{\mathrm{K}}}\right)=\left(\frac{\mathrm{G}_{\mathrm{L}}}{\mathrm{F}_{\mathrm{L}}}\right)=1+\delta
$$

A Equação (3) evidencia a existência de um diferencial de produtividade entre o setor exportador e o setor não exportador. Nesse caso, na ausência de externalidades, e dado um conjunto de preços, $\delta$ será igual a zero $(\delta=0)$, refletindo uma alocação de recursos entre ambos os setores que maximiza o produto nacional. Por outro lado, caso as externalidades estejam presentes, $\delta$ será maior do que zero $(\delta>0)$ indicando que as produtividades marginais dos fatores de produção do setor exportador são maiores do que as do setor não exportador. Nesse caso, Feder (1982) aponta que são diversos os fatores que podem ocasionar a maior produtividade do setor exportador, dentre eles está a maior competição existente no mercado internacional, que induz as firmas a investirem em técnicas mais eficientes de produção e de gerenciamento, bem como na qualificação da mão de obra. 
O produto da economia é definido por $Y=N+X$, e diferenciando-se essa equação e as Equações (01) e (03), tem-se:

$$
\begin{aligned}
& \dot{\mathrm{N}}=\mathrm{F}_{\mathrm{K}} \mathrm{I}_{\mathrm{n}}+\mathrm{F}_{\mathrm{L}} \dot{\mathrm{L}}_{\mathrm{n}}+\mathrm{F}_{\mathrm{X}} \dot{\mathrm{X}} \\
& \dot{\mathrm{X}}=\mathrm{G}_{\mathrm{K}} \mathrm{I}_{\mathrm{x}}+\mathrm{G}_{\mathrm{L}} \dot{\mathrm{L}}_{\mathrm{x}} \\
& \dot{\mathrm{Y}}=\dot{\mathrm{N}}+\dot{\mathrm{X}}
\end{aligned}
$$

Sendo que $I_{n}$ e $I_{x}$ constituem, respectivamente, os investimentos brutos nos setores não exportador e exportador, $\dot{L}_{n}$ e $\dot{L}_{x}$ são as mudanças setoriais no fator de produção trabalho do setor não exportador e exportador, e $F_{x}$ é o efeito marginal (spillover) gerado pelo setor exportador sobre o setor não exportador.

Definindo o investimento total como $I=I_{n}+I_{x}$, o crescimento do fator de produção trabalho como $\dot{L}=\dot{L}_{n}+\dot{L}_{x}$, usando as Equações (03)-(05) na Equação (06), fazendo algumas manipulações algébricas e, ainda, assumindo que exista uma relação linear entre a produtividade marginal do trabalho em um dado setor e a produção média por trabalhador na economia, obtém-se a taxa de crescimento da economia, formalizada da seguinte maneira:

$$
\frac{\dot{\mathrm{Y}}}{\mathrm{Y}}=\alpha\left(\frac{\mathrm{I}}{\mathrm{Y}}\right)+\beta\left(\frac{\dot{\mathrm{L}}}{\mathrm{L}}\right)+\left[\frac{\delta}{(1+\delta)}+\mathrm{F}_{\mathrm{x}}\right]\left(\frac{\dot{\mathrm{X}}}{\mathrm{X}}\right)\left(\frac{\mathrm{X}}{\mathrm{Y}}\right)
$$

$\mathrm{Na}$ formulação apresentada em (07) o parâmetro alfa $\alpha$ deve ser interpretado como a produtividade marginal do capital do setor não exportador, ao invés da produtividade marginal do capital da economia como um todo. Assim, a taxa de crescimento do produto da economia é composta da contribuição da taxa de crescimento dos fatores de produção, capital $(K)$ e trabalho $(L)$, bem como dos efeitos do setor exportador.

Um ponto importante a destacar no tocante à Equação (07) é que ainda não foi considerada a externalidade intersetorial, denotada por $F_{x}$. Para especificar esse efeito, Feder (1982) assume que as exportações afetam a produção do setor não exportador com uma elasticidade constante:

$$
N=F\left(K_{n}, L_{n}, X\right)=X^{\theta} \psi\left(K_{n}, L_{n}\right)
$$


Considerando $\theta$ como parâmetro, e derivando $N$ com relação à $X$ :

$$
\frac{\partial \mathrm{N}}{\partial \mathrm{X}} \equiv \mathrm{F}_{\mathrm{x}}=\theta\left(\frac{\mathrm{N}}{\mathrm{X}}\right)
$$

Substituindo a Equação (09) na Equação (07), e fazendo algumas manipulações algébricas, deriva-se a taxa de crescimento do produto, considerando o efeito da externalidade do setor exportador sobre o setor não exportador:

$$
\frac{\dot{\mathrm{Y}}}{\mathrm{Y}}=\alpha \frac{\mathrm{I}}{\mathrm{Y}}+\beta \frac{\dot{\mathrm{L}}}{\mathrm{L}}+\left(\frac{\delta}{1+\delta}-\theta\right) \frac{\dot{\mathrm{X}} \mathrm{X}}{\mathrm{X}} \overline{\mathrm{Y}}+\theta \frac{\dot{\mathrm{X}}}{\mathrm{X}}
$$

Todavia, essa formulação não possibilita distinguir o efeito das externalidades do efeito alocativo das exportações. Feder (1982), então, pressupõe que a intensidade do efeito externalidade é uma função da relação entre a produção do setor não exportador e a produção do setor exportador. Desta forma, quanto menor for a participação do setor exportador no total da economia, maior será o efeito das externalidades. Assim, conforme essa argumentação, após algumas manipulações algébricas, a formulação final do modelo é:

$$
\frac{\dot{\mathrm{Y}}}{\mathrm{Y}}=\alpha\left(\frac{\mathrm{I}}{\mathrm{Y}}\right)+\beta\left(\frac{\dot{\mathrm{L}}}{\mathrm{L}}\right)+\lambda\left(\frac{\dot{\mathrm{X}}}{\mathrm{X}}\right)\left(\frac{\mathrm{X}}{\mathrm{Y}}\right)+\varnothing\left(\frac{\dot{\mathrm{X}}}{\overline{\mathrm{X}}}\right)\left(\frac{\mathrm{Y}-\mathrm{X}}{\mathrm{Y}}\right)
$$

A equação definida em (11) será utilizada como base para a especificação do modelo empírico a ser descrito na seção 3.

É importante aqui ressaltar que é possível encontrar na literatura uma derivação do modelo original de Feder (1982), desenvolvido por Crespo-Cuaresma e Wörz (2003). Nesse modelo, os autores refinam a hipótese de crescimento liderado pelas exportações, dando destaque para a composição da pauta exportadora. A hipótese é a de que as indústrias mais intensivas em tecnologia possuem maior potencial de produtividade e spillovers do que as indústrias menos intensivas em tecnologia; em consequência disso, as indústrias de alta tecnologia lideram o processo de crescimento econômico.

Não obstante esse refinamento, justifica-se aqui a utilização do modelo original de Feder (1982), porque se busca identificar a magnitude dos efeitos indiretos das exportações no crescimento econômico 
das microrregiões, sem levar em consideração a composição da pauta de exportação.

Embora cientes da importância da pauta exportadora para o crescimento econômico -conforme destacado em Crespo-Cuaresma e Wörz (2003) -, a opção deste trabalho foi considerar as exportações agregadas e seu efeito no dinamismo econômico [modelo à la Feder(1982)], especialmente por não existir nenhuma evidência empírica sobre qualquer efeito das exportações no crescimento econômico regional do Brasil. Neste sentido, a análise agregada da inserção internacional dará pistas sobre efeitos setoriais mais específicos, que poderão ser estudados num segundo momento.

\subsection{Aplicações empíricas do modelo de Feder ${ }^{l}$}

Quando se investiga os efeitos das exportações sobre o crescimento econômico à luz do modelo de Feder, procura-se, na verdade, mensurar os efeitos indiretos que as exportações têm sobre o crescimento. Nesse caso, duas hipóteses centrais do modelo são testadas: i) se existe um diferencial de produtividade entre o setor exportador e setor não exportador; ii) se o setor exportador gera uma externalidade (spillover) positiva sobre o setor não exportador. Na presente seção, descrevem-se alguns trabalhos que estimaram o modelo de Feder (1982).

Neste caso, inicia-se justamente com o artigo original de Feder (1982), que, após a derivação do modelo teórico, estima-o empiricamente. Em sua análise, o autor utilizou dados de países em desenvolvimento no período compreendido entre 1964 e 1973. O modelo foi estimado por Mínimos Quadrados Ordinários, considerando os valores médios das variáveis. Os resultados mostraram que o diferencial de produtividade induz o crescimento econômico, o que corrobora a hipótese de que o setor exportador possui uma produtividade marginal dos fatores superior à do setor não exportador. Além desse diferencial de produtividade, as estimações também mostraram a

1 Existem outros estudos que avaliam os efeitos indiretos das exportações no crescimento econômico a partir do modelo teórico de Crespo-Cuaresma e Wörz (2003), como, por exemplo, Gani (2009). No entanto, por conta da limitação de espaço no corpo do texto, só serão discutidos os trabalhos que avaliaram os efeitos das exportações no crescimento a partir do modelo teórico de Feder (1982). 
existência de uma externalidade positiva do setor exportador sobre o setor não exportador. As demais variáveis inseridas no modelo apresentaram os seus comportamentos esperados, tendo em vista que os coeficientes associados às variáveis investimento e força de trabalho apresentaram sinais positivos e estatisticamente significativos. Por fim, com base nos resultados estimados, Feder mostrou que o investimento no setor exportador tem mais efeito sobre o crescimento da economia do que o investimento no setor não exportador, e que esse efeito é maior quanto menor for a exposição do país ao comércio internacional.

Ibrahim (2002) estimou o modelo de Feder (1982) para seis países asiáticos (Hong Kong, Coreia do Sul, Malásia, Filipinas, Cingapura e Tailândia) com dados em séries de tempo. Algumas hipóteses do modelo de Feder foram corroboradas pelas estimativas. Dos seis países analisados, quatro apresentaram diferenciais de produtividade entre o setor exportador e não exportador. Ademais, para todos os países analisados, a produtividade é maior no setor exportador do que no setor não exportador. Por fim, com exceção das Filipinas, em todos os outros países existe uma externalidade positiva do setor exportador sobre a economia. No entanto, o autor faz a ressalva de que esse efeito tende a ser mais forte em países menos desenvolvidos, sendo mitigado para países mais desenvolvidos. Ibrahim aponta, ainda, que a produtividade do setor exportador também é influenciada pelo tamanho do país e pela orientação da política comercial.

Seijo (2000) estimou o modelo de Feder para um grupo de 72 países em desenvolvimento. Utilizando dados em corte transversal e estimando o modelo por Mínimos Quadrados Ordinários, o autor verificou que as exportações, por meio das externalidades geradas, têm efeitos positivos sobre o setor não exportador, em consequência, sobre o crescimento econômico. Para testar a robustez do modelo, o autor dividiu a amostra em dois grupos de países em desenvolvimento (médio e baixo), conforme o nível de renda dos países. Para ambas as amostras, os resultados confirmaram o resultado anterior de que as exportações geram uma externalidade positiva sobre o setor não exportador. Por fim, na última rodada de estimações, o autor dividiu a amostra, sob o ponto de vista geográfico, em três grupos: África, América do Sul e Ásia. Considerando esses grupos, apenas para os países africanos o coeficiente associado às externalidades foi positivo e estatisticamente significativo, já para os outros dois 
grupos (América Latina e Ásia) o coeficiente foi positivo, mas não significativo.

Mehdi e Shahryar (2012) estimaram o modelo de Feder para o Irã, considerando o período de 1961 a 2006. O modelo empírico foi estimado pela técnica de séries de tempo, para os seguintes setores: indústria/mineração, agrícola e serviços. Os autores objetivaram estimar quais os efeitos das exportações desses setores sobre os respectivos valores adicionados (utilizado como proxy para o crescimento dos setores). Em todas as estimações, os autores verificaram que as exportações têm efeitos positivos, e estatisticamente significativos, sobre os valores adicionados dos setores analisados. Os resultados mostraram que o aumento de 1,00\% nas exportações da indústria/ mineração majora o valor adicionado deste setor em 0,053\%. Já para o setor agrícola estimou-se que uma elevação de $1,00 \%$ nas suas exportações eleva o respectivo valor adicionado em $0,034 \%$. Por fim, para o setor de serviços, o efeito foi um pouco menor do que o verificado nos outros setores, em que uma elevação de 1,00\% nas exportações deste setor eleva em $0,019 \%$ o seu valor adicionado.

Diferentemente dos estudos anteriores, Cantú e Mollik (2003), em vez de utilizarem dados de países, estimaram o modelo de Feder (1982) considerando os dados de 32 estados mexicanos, no período de 1993 e 1998. Os autores também inovaram no aspecto metodológico, com a estimação do modelo por meio da metodologia de dados em painel. Em todos os modelos estimados, o capital não apresentou significância estatística, e o crescimento do fator de produção trabalho (em que a proxy utilizada foi o crescimento populacional) teve sinal negativo, contrário ao esperado. Ademais, não obstante os efeitos das externalidades serem positivos e estatisticamente significativos, foram muito pequenos, próximos de zero, tanto no modelo de efeitos fixos quanto no modelo de efeitos aleatórios. Assim, os resultados encontrados por Cantú e Mollik corroboraram, em parte, os pressupostos do modelo de Feder.

É de Galimberti e Caldart (2010) o único trabalho encontrado na literatura nacional que estima o modelo de Feder para a economia brasileira. Nesse estudo, seguindo a mesma linha do trabalho de Cantú e Mollik (2003), também foram utilizados dados espaciais, oriundos de 22 municípios pertencentes ao Corede Serra, região localizada no Rio Grande do Sul. O período de tempo considerado 
pelos autores foi de 1997 a 2004. Não obstante utilizarem dados espaciais, os autores estimaram o modelo empírico por meio do método de Mínimos Quadrados Ordinários (MQO), considerando os valores médios das variáveis. Verificaram que existe um diferencial de produtividade entre o setor exportador e o setor não exportador, sendo que esse diferencial tem um efeito positivo, e estatisticamente significativo, sobre o crescimento econômico da região. Por outro lado, a outra hipótese central do modelo teórico, que trata do efeito da externalidade do setor exportador sobre o setor não exportador, não foi confirmada pelos resultados.

É importante ressaltar que o presente trabalho está alinhado com o estudo de Galimberti e Caldart (2010) no que tange à utilização do modelo de Feder para avaliar os efeitos das exportações sobre o crescimento econômico. No entanto, a presente pesquisa avança em relação ao trabalho anterior nos seguintes aspectos. Primeiro, Galimberti e Caldart (2010) fazem o seu estudo considerando apenas os municípios pertencentes ao Corede Serra, região localizada no Rio Grande do Sul, ao passo que o presente estudo é mais abrangente, pois utiliza todas as microrregiões brasileiras. ${ }^{2}$ Segundo, Galimberti e Caldart (2010), não obstante a utilização de dados espaciais, estimaram o modelo empírico por meio de Mínimos Quadrados Ordinários (MQO), considerando os valores médios das variáveis, o que pode trazer sérias consequências nos resultados obtidos, tendo em vista o não controle da dependência espacial das variáveis. Já na presente pesquisa será construído um painel de dados e o modelo empírico será estimado pelas recentes técnicas da econometria espacial, em forma de dados em painel, o que aumenta a robustez dos resultados estimados.

\footnotetext{
2 Destaca-se novamente a importância do uso de microrregião em vez de município quando a variável a ser considerada são as exportações, especialmente visando minimizar subestimações ou superestimações que podem ocorrer por serem registrados apenas os municípios que têm empresas exportadoras, ignorando a possibilidade de os produtores dessas exportações estarem nos municípios próximos.
} 


\section{Metodologia}

Como ressaltado na introdução, os dados analisados na presente pesquisa terão um recorte geográfico microrregional, considerando todas as 558 microrregiões brasileiras. As microrregiões são classificadas pelo IBGE (1991) e são identificadas pela interação entre as áreas de produção e os locais de beneficiamento, e pela possibilidade de atender às populações através do comércio de varejo ou atacado ou dos setores básicos. Desta forma, o ponto fundamental para determinar os espaços microrregionais é a estrutura produtiva existente.

Por conta da natureza dos dados, que são espaciais, é bastante comum na literatura especializada a realização de uma análise exploratória denominada AEDE (Análise Exploratória de Dados Espaciais), a qual informa a existência ou não de efeitos de transbordamento nas variáveis, bem como auxilia na especificação do modelo econométrico.

\subsection{Análise exploratória dos dados espaciais}

No presente estudo será realizada uma análise exploratória de dados espaciais (doravante AEDE). Essa análise tem como objetivo descrever a distribuição espacial do crescimento econômico das microrregiões brasileiras e relacionar esse crescimento à distribuição espacial das exportações. Com isso, será possível identificar os padrões de associação espacial e a identificação de diferentes regimes espaciais.

Para se implementar a AEDE é necessária a adoção de uma matriz de ponderação espacial $(W) .{ }^{3}$ Conforme Almeida (2012, p. 76), essa é uma matriz quadrada de ordem $n$ por $n$, cujos elementos denotam o grau de conexão espacial entre as microrregiões em análise, seguindo algum critério de proximidade. No presente estudo, o critério de proximidade será baseado na contiguidade (com convenção do tipo torre, rainha e do vizinho mais próximo), em que se parte do pressuposto de que as microrregiões contíguas possuem uma interação

3 Conforme Almeida et al. (2012, p.39) "essa matriz é a forma de se expressar um determinado arranjo espacial das interações resultantes do fenômeno a ser estudado. Por exemplo, é razoável supor que, no estudo de vários fenômenos, regiões vizinhas tenham uma interação mais forte entre si do que regiões que não são contíguas". 
mais forte do que as microrregiões que não são contíguas. Assim, o elemento $w_{i j}$ da matriz de ponderação espacial $(W)$ terá valor igual a 1 quando duas microrregiões forem contíguas, e 0 em caso contrário.

Por convenção, o elemento $w_{i i}$ será igual a zero, pois uma microrregião não pode ser vizinha de si mesma; em consequência disto, a diagonal principal da matriz de ponderação espacial $(W)$ será composta por zeros. $\mathrm{Na}$ implementação da AEDE serão utilizadas as seguintes técnicas: testes de autocorrelação espacial global (univariada e bivariada); e teste de autocorrelação espacial local, este com o auxílio de mapas de clusters LISA.

\subsubsection{Autocorrelação espacial global (univariada)}

A autocorrelação espacial global permite identificar se a distribuição espacial de uma determinada variável ocorre de forma aleatória ou não. Caso a distribuição espacial seja considerada aleatória, isto significa que o comportamento desta variável na região $i$ não é influenciado pelo comportamento da mesma variável na região $j$. Destaca-se que a análise será feita mediante a aplicação da estatística I de Moran (1948), a qual é definida da seguinte forma:

$$
\mathrm{I}=\frac{\mathrm{n}}{\mathrm{S}_{0}} \frac{\mathrm{z}^{\prime} \mathrm{Wz}}{\mathrm{Z}^{\prime} \mathrm{z}}
$$

Na presente pesquisa, $n$ denota o número de microrregiões; $z$ é o valor do PIB das microrregiões (padronizado); $W z$ representa os valores médios dos PIBs das microrregiões (padronizados nos vizinhos), e definidos conforme a matriz de ponderação espacial adotada $(W)$; $S_{0}$ é o somatório de todos os elementos da matriz de ponderação espacial $(W)$.

A hipótese nula a ser testada é a de que a distribuição espacial do PIB é aleatória. O valor esperado do teste é -[1/(n-1)]. Caso exista aleatoriedade na distribuição espacial das exportações entre as microrregiões, a estatística $I$ de Moran deve ser igual ao seu valor esperado, conforme o nível de significância adotado; caso contrário, rejeita-se a hipótese nula. Um valor de $I$ maior do que o seu valor esperado indica uma autocorrelação espacial positiva no crescimento 
econômico das microrregiões, e um valor de $I$ abaixo do seu valor esperado corresponde a uma autocorrelação espacial negativa. ${ }^{4}$

\subsubsection{Autocorrelação espacial global (bivariada)}

A autocorrelação espacial global destacada na subseção anterior também pode ser empregada em um contexto bivariado (JUNIOR; ALMEIDA, 2009). Neste caso, a proposta é descobrir se os valores de uma variável observada em uma determinada microrregião têm uma relação sistemática com os valores de uma outra variável observada nas microrregiões vizinhas. Em termos formais, é possível calcular a estatística $I$ de Moran para duas variáveis diferentes, $y$ e $x$.

$$
\mathrm{I}^{\mathrm{yx}}=\frac{\mathrm{n}}{\sum_{\mathrm{i}} \sum_{\mathrm{j}} \mathrm{w}_{\mathrm{ij}}} \frac{\sum_{\mathrm{i}} \sum_{\mathrm{j}}\left(\mathrm{x}_{\mathrm{i}}-\overline{\mathrm{x}}\right) \mathrm{w}_{\mathrm{ij}}\left(\mathrm{y}_{\mathrm{i}}-\overline{\mathrm{y}}\right)}{\sum_{\mathrm{i}}\left(\mathrm{x}_{\mathrm{i}}-\overline{\mathrm{x}}\right)^{2}}
$$

Como visto no contexto univariado, os valores positivos e negativos do $I$ de Moran bivariado denotam concentração e dispersão espaciais, respectivamente. Destaca-se que, para a implementação desta estatística, $y$ será definido como a taxa de crescimento econômico das microrregiões, enquanto que $x$ será: a taxa de crescimento das exportações das microrregiões; a participação do capital físico no PIB; e a taxa de crescimento da população.

\subsubsection{Autocorrelação espacial local}

Além da análise da existência de autocorrelação global, como fora destacado anteriormente, também será feita uma averiguação da existência de uma possível autocorrelação local para a distribuição espacial das exportações das microrregiões do Brasil. Almeida (2012, p. 120) advoga que averiguar a existência de autocorrelação local é importante porque a análise da autocorrelação global pode ocultar outros padrões locais de autocorrelação. Na presente pesquisa, a au-

4 Uma autocorrelação espacial positiva significa que uma microrregião com elevado (baixo) PIB está rodeada por microrregiões que também possuem o PIB elevado (baixo). Quando a autocorrelação espacial é negativa, uma microrregião com elevado (baixo) PIB está rodeada por microrregiões com PIB baixo (elevado). 
tocorrelação espacial local será testada por meio da estatística $I$ de Moran local, a qual pode ser formalizada da seguinte maneira:

$$
I_{i}=z_{i} \sum_{j=1}^{J} w_{i j} z_{j}
$$

Onde $z_{i}$ corresponde ao valor das exportações da microrregião $i$ padronizada; $w_{i j}$ denota o elemento da matriz de ponderação espacial $(W)$, e $z_{j}$ corresponde ao valor das exportações da microrregião $j$ padronizada. Assumindo a condição de normalidade, o valor esperado da estatística $I_{i}$ será: $E\left[I_{i}\right]=-w_{i} /(n=1)$.

Cabe ressaltar que a análise da estatística $I_{i}$ de Moran aqui utilizada é muito mais complexa do que a análise do $I$ de Moran global. Isto porque, na análise local, cada observação possuirá a sua estatística $I_{i}$, obtendo-se com isto $n$ computações da estatística $I_{i}$ com os respectivos níveis de significância. Assim, para facilitar a análise deste conjunto de informações, será utilizado o mapa de cluster do tipo LISA (Local Indicator of Spatial Association), que exibe apenas as microrregiões que possuem o $I_{i}$ de Moran significativo.

3.2. Modelo empírico, fonte dos dados e estratégia de estimação dos parâmetros

O efeito das exportações sobre o crescimento econômico das microrregiões brasileiras será analisado à luz da Equação (11) do modelo teórico de Feder (1982), descrito na seção 2, sendo que a formulação empírica dessa equação é especificada da seguinte maneira:

$$
\begin{aligned}
& \text { TPIB }_{j \mathrm{t}}=\beta_{0}+\beta_{1} \mathrm{INCF}_{\mathrm{jt}}+\beta_{2} \text { FTRAB }+\beta_{3}\left(\text { CRESX }_{\mathrm{jt}} * \text { PARTX }_{\mathrm{jt}}\right) \\
& +\beta_{4}\left(\left[\operatorname{CRESX}_{\mathrm{jt}}\left(1-\operatorname{PARTX}_{\mathrm{jt}}\right)\right]+\beta_{5} \mathrm{DC}_{\mathrm{jt}}+\mathrm{u}_{\mathrm{jt}}\right.
\end{aligned}
$$

Em que: $T P I B_{j t}$ denota a taxa de crescimento do Produto Interno Bruto (PIB) da j-ésima microrregião no tempo $t ; I N C F_{j t}$ é o investimento em capital físico em relação ao PIB da $j$-ésima microrregião no tempo $t ; F T R A B_{j t}$ é a taxa de crescimento da população $j$-ésima microrregião no tempo $t$; $C R E S X_{j t}$ é a taxa de crescimento das ex- 
portações da j-ésima microrregião no tempo $t$; PARTX $X_{j t}$ corresponde à participação das exportações no PIB da $j$-ésima microrregião no tempo $t$; DC refere-se a uma dummy de crise ("um" para 2008, 2009 e 2010, e "zero" para os demais anos"), e é o termo de erro aleatório.

A variável $T P I B_{j t}$ foi mensurada com base na variação percentual do PIB do ano $t$ em relação ao PIB do ano $t$-1; os dados dos PIBs das microrregióes foram coletados junto à base de dados do IPEADATA para o período de 1999 a 2010 ( $\mathrm{R} \$$, preços constantes de 2000). Para mensurar a variável que denota o investimento em capital fixo $\left(I N C F_{j t}\right)$ foi utilizado como proxy o valor dos estabelecimentos. ${ }^{6}$ Já o FTRAB $B_{j t}$ foi coletado junto ao IPEADATA. A variável $C R E S X_{j t}$ foi mensurada com base na variação percentual das exportações do ano $t$ em relação as exportações do ano $t-1$; e os dados das exportações foram obtidos junto ao sítio da Aliceweb originalmente para os municípios, mas para a execução da presente pesquisa foram agregados para as microrregiões. A variável PARTX $X_{j t}$, que é a participação das exportações no PIB da $j$-ésima microrregião, foi obtida por meio da divisão das exportações pelo PIB. Detalhes sobre as variáveis e de como elas foram mensuradas encontram-se no Apêndice B.

É importante mencionar que o procedimento de construção das variáveis é distinto do utilizado no trabalho original de Feder (1982): enquanto aqui se define em termos de taxas de crescimento calculadas a partir da variação percentual da variável de interesse no ano t em relação à mesma variável no ano t-1, Feder (1982) utilizou as taxas de crescimento médio do período obtidas por meio de regressões log-lin. Justifica-se essa diferença porque Feder (1982) estimou o seu modelo com base na metodologia de cross-section, enquanto que no presente trabalho a proposta foi construir um banco de dados em forma de painel a partir das variações percentuais anuais. Um painel de dados de uma determinada variável é um conjunto de observações no qual as unidades de cross-section (as microrregiões) são observadas ao longo de $t$ períodos de tempo; com isso, um painel de

5 Tendo em vista que a partir de 2008 os países em geral foram atingidos pela crise financeira mundial, então optou-se pela inclusão de uma dummy na estimativa (15), buscando identificar o impacto que a crise proporcionou no crescimento econômico das microrregiões brasileiras.

6 O número de estabelecimentos de cada microrregião foi auferido na RAIS. Considerando o total de estabelecimentos do país e dividindo pelo total de investimento, fez-se o rateio, por meio do qual se mensurou o capital físico de cada microrregião. Importante destacar que se fez uma correlação entre essa variável e o real capital físico do país e o resultado foi de uma correlação de 0,98 . 
dados consiste em combinar dados de cross-section e séries temporais (WOOLDRIDGE, 2002).

A ideia de construir um banco de dados em forma de painel encontra respaldo na literatura especializada. Conforme Elhorst (2003) e Hsiao (2005), a estimação do modelo econométrico por meio da metodologia de dados em painel obtém resultados mais robustos do que os da metodologia de cross-section. Isso ocorre porque o painel de dados é geralmente mais informativo; contém mais variação e menos colinearidade entre as variáveis; o seu uso resulta em um aumento nos graus de liberdade; o que por sua vez eleva a eficiência na sua estimação.

O método de dados em painel assume que as unidades de crosssection são independentes entre si, mas quando as observações de cross-section são unidades espaciais (como as microrregiões), esta hipótese é inapropriada, pois os dados são suscetíveis à presença de efeitos específicos observáveis e não observáveis, fazendo com que os resíduos de uma unidade de cross-section seja correlacionado com o resíduo de outra unidade cross-section (DRISCOLL; KRAAY, 1995). Desta forma, é necessário adaptar o modelo de painel de dados para uma provável dependência espacial entre as unidades espaciais de cross-section.

A estimação do modelo empírico por painel de dados espaciais possibilita controlar a heterogeneidade espacial não observável que se manifesta nos parâmetros da regressão, principalmente nos interceptos. Isto ocorre porque a heterogeneidade espacial não observável acaba exercendo uma influência sobre o intercepto, fazendo este variar conforme a microrregião. Além disto, a heterogeneidade espacial não observável também pode influenciar o termo de erro aleatório (ALMEIDA, 2012). Desta forma, a heterogeneidade espacial deve ser controlada ou por meio da utilização de modelos de efeitos fixos ou de efeitos aleatórios, e a escolha entre os modelos será feita com base no teste de Hausman.

Conforme Almeida (2012), a especificação geral do modelo de efeitos fixos espacial pode ser representada da seguinte forma:

$$
\begin{gathered}
\mathrm{y}_{\mathrm{t}}=\alpha+\rho \mathrm{W}_{1} \mathrm{y}_{\mathrm{t}}+\mathrm{X}_{\mathrm{t}} \beta+\mathrm{W}_{1} \mathrm{X}_{\mathrm{t}} \tau+\xi_{\mathrm{t}} \\
\xi_{\mathrm{t}}=\lambda \mathrm{W}_{2} \xi_{\mathrm{t}}+\varepsilon_{\mathrm{t}}
\end{gathered}
$$


Já a especificação geral do modelo de efeitos aleatórios espacial pode ser formalizada do seguinte modo:

$$
\begin{gathered}
y_{t}=\rho W y_{t}+X_{t} \beta+W X_{t} \tau+\xi_{t} \\
\xi_{t}=\alpha+\lambda W \xi_{t}+\varepsilon_{t}
\end{gathered}
$$

Em que: $\alpha$ é a heterogeneidade não observada; $\rho$ e $\lambda$ são parâmetros espaciais escalares; $\tau$ é um vetor de coeficientes espaciais; $W$ é a matriz de ponderação espacial; $W_{l} y_{t}$ corresponde à defasagem espacial da variável dependente; $W_{1} X_{t}$ são as variáveis explicativas exógenas defasadas espacialmente; $W_{2} \xi_{t}$ representa o termo de erro defasado espacialmente. Partindo desses modelos gerais e impondo algumas restrições acerca do comportamento dos parâmetros $\rho, \tau$ e $\lambda$, podemse especificar diferentes formas de modelos de efeitos fixos e de efeitos aleatórios espaciais.

\section{Análise dos resultados}

Nos anos de 2000, o Brasil apresentou taxas de crescimento do PIB claudicante, inferiores às observadas na década de 1970, mas superiores às auferidas nos anos de 1980 e 1990. Tal dinâmica de crescimento ainda sofreu com a crise financeira iniciada em 2008 (Figura 1).

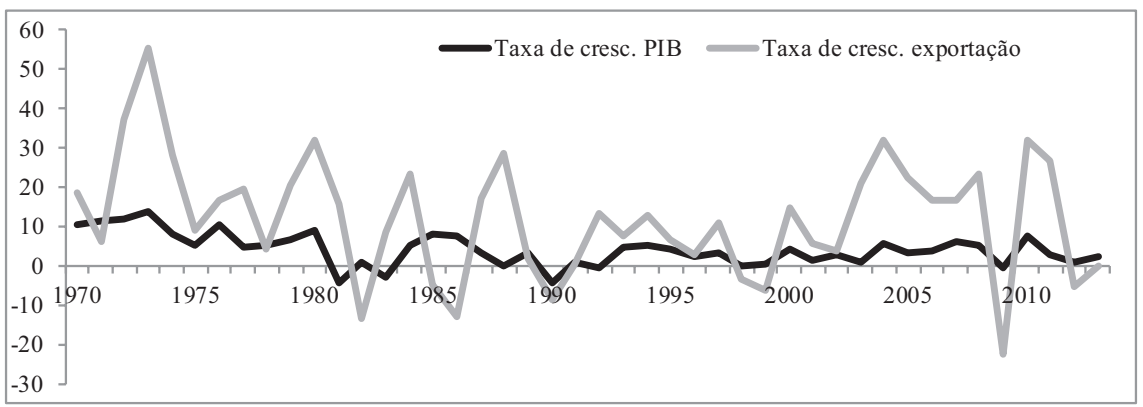

Figura 1 - Taxa de crescimento do PIB e das exportações brasileiras (\%) - 1970 a 2013

Fonte: Elaborado pelos autores a partir dos dados do Ipeadata. 
Ainda com relação à Figura 1 , quando comparamos a dinâmica do crescimento com a dinâmica das exportações, é possível notar certa correlação entre as variáveis, em que uma elevação das exportações é associada a uma elevação do produto. No caso de 2008/2009, quando a atividade econômica declinou, as exportações apresentaram uma queda aguda, sendo a maior em todo o período analisado.

É natural que exista uma relação direta entre as exportações e o crescimento do produto, tendo em vista que as exportações fazem parte da demanda agregada. Contudo, o aspecto mais interessante a destacar são os efeitos indiretos das exportações, os quais ocorrem devido às externalidades geradas pelo setor exportador sobre toda a economia, como salientado no modelo teórico de Feder (1982).

Como a presente pesquisa utiliza dados de natureza espacial, isto é, das microrregiões brasileiras, o comportamento das exportações (ou do crescimento do PIB) de uma determinada microrregião pode ser afetado pelo comportamento das exportações (ou do crescimento do PIB) das microrregiões circunvizinhas, evidenciando uma dependência espacial entre as microrregiões; esta questão pode ser melhor visualizada por meio da análise da Figura 2.

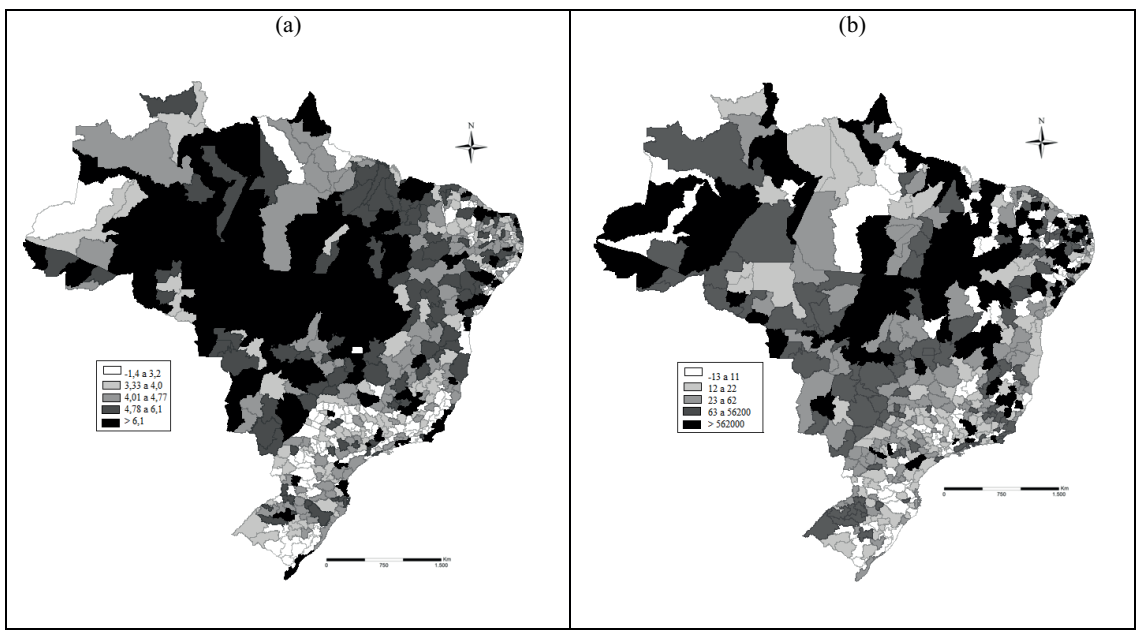

Figura 2 - Taxa média de crescimento do PIB (a), taxa média de crescimento das exportações (b) - Microrregiões do Brasil -período de 2000 a 2010

Fonte: Elaborado pelos autores a partir dos dados do Ipeadata e da AliceWeb. 
Na Figura 2, mapa (a), observa-se a distribuição espacial da taxa média de crescimento econômico das microrregiões no período compreendido entre 2000 e 2010; e no mapa (b) reporta-se a taxa média de crescimento das exportações das microrregiões nesse mesmo período. A cor mais escura informa aquelas microrregiões que tiveram altas taxas de crescimento, ao passo que a cor mais clara informa o oposto. A constatação imediata é a de que as taxas de crescimento variaram muito entre as microrregiões, evidenciando que o desempenho econômico das microrregiões é bastante heterogêneo, sendo que muitas microrregiões conseguiram um crescimento tanto do PIB quanto das suas exportações bem superior à média brasileira $(68 \% \mathrm{e}$ $74 \%$ das microrregiões, respectivamente).

Uma análise mais minuciosa dos dados das exportações revela que a maior parte destas estão concentradas em algumas microrregiões, localizadas, sobretudo, nas regiões Sudeste e Sul, com um grande vazio de microrregiões exportadoras nas regiões Norte e Nordeste (Figura 3, a-b). A título de exemplo, em 2010 o Brasil teve 464 microrregiões exportadoras, sendo que, deste total, 246 estavam localizadas nas regiões Sudeste e $\mathrm{Sul}^{7}$, as quais responderam, conjuntamente, por $79,5 \%$ do total exportado pelo Brasil.

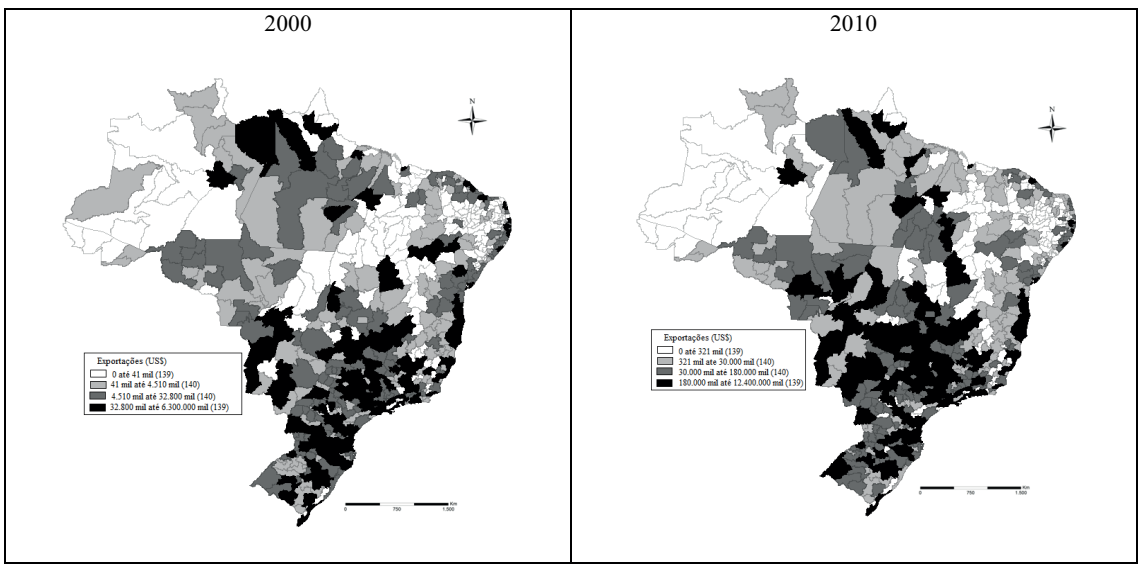

Figura 3 - Distribuição das exportações entre as microrregiões do Brasil - anos de 2000 e de 2010

Fonte: Elaborado pelos autores no software GeoDa a partir dos dados da AliceWeb.

7 Região Sudeste: 62 em São Paulo, 62 em Minas Gerais, 17 no Rio de Janeiro, 12 no Espírito Santo. Região Sul: 39 no Paraná, 34 no Rio Grande do Sul, 20 em Santa Catarina. 
A respeito desta grande heterogeneidade espacial, Perobelli e Haddad (2002) apontam que essa ocorre devido a questões estruturais do setor produtivo, pela disponibilidade de recursos naturais, incentivos governamentais, custos inerentes ao transporte e facilidade ao mercado externo. A importância da infraestrutura de transporte também é destacada no trabalho de Junior e Almeida (2009), em que os autores mostraram que as microrregiões que apresentaram alto valor exportado estão rodeadas por uma grande disponibilidade de infraestrutura de transporte (como rodovias, ferrovias e portos), indicando que a presença de uma ampla disponibilidade de escoamento da produção condiciona o desempenho exportador da microrregião.

Esta grande disparidade regional no que tange à concentração das exportações pode, ainda, ser observada por meio da análise do mapa de clusters LISA (Figura 4). Neste mapa é possível notar três grandes clusters "baixo-baixo", um na região Norte, outro na região Nordeste, e um terceiro seguindo entre as regiões Nordeste e Sudeste, não tendo nenhum cluster "alto-alto" na região Norte e Nordeste. Ou seja, é necessário ampliar a competitividade brasileira para que mais espaços consigam se inserir fortemente no mercado internacional.

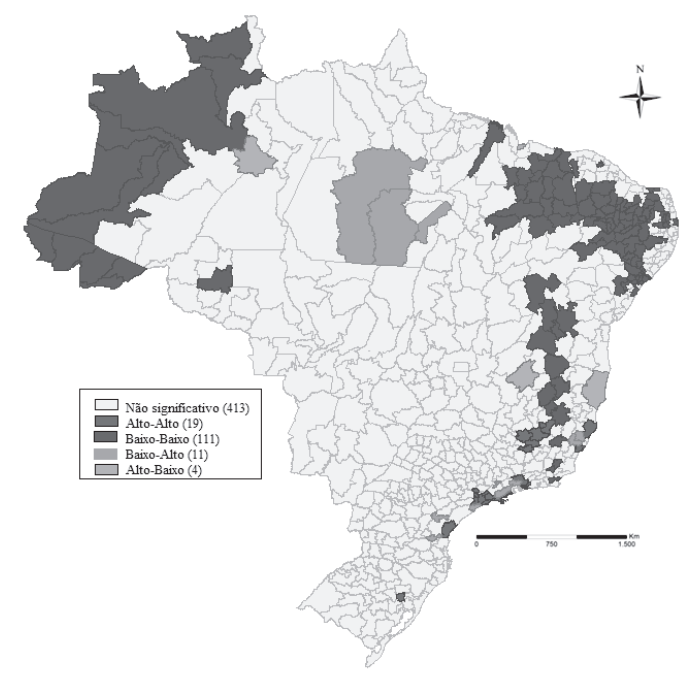

Figura 4 - Mapa de clusters LISA para as exportações - microrregiões do Brasil - ano 2010

Fonte: Elaborado pelos autores no software GeoDa a partir dos dados da AliceWeb. 
A partir do contexto acima exposto, o próximo passo é investigar a existência de uma dependência espacial entre as microrregiões, por meio da análise da estatística I de Moran. Como o I de Moran é positivo, e estatisticamente significativo, pode-se afirmar que existe uma autocorrelação espacial positiva tanto para o PIB quanto para as exportações. Como consequência disso, é possível inferir que as microrregiões que apresentaram elevadas (baixas) taxas de crescimento do PIB (ou das exportações) estão rodeadas por microrregiões que também apresentaram altas (baixas) taxas de crescimento do produto (ou das exportações).

Na Tabela 1, além do I de Moran univariado, também foi avaliado o I de Moran bivariado. Na análise bivariada é possível identificar se as microrregiões que apresentam altas (baixas) taxas de crescimento de uma determinada variável $Y$ estão rodeadas por microrregiões que apresentam altas (baixas) taxas de crescimento de uma outra variável $X$.

Mais uma vez, o I de Moran apresentou sinal positivo e significância estatística, mostrando que o crescimento econômico das microrregiões é influenciado pelo desempenho das exportações das microrregiões do seu envoltório. Isto é, corrobora-se a hipótese de que o maior dinamismo econômico está se centrando, especialmente, naquelas microrregiões em que o crescimento das exportações é maior, potencializando um efeito de transbordamento dos resultados no envoltório dessas regióes.

Destaca-se que a análise bivariada também foi realizada para as outras variáveis do modelo empírico, pois, como apontado no modelo de Feder (1982), tanto o capital quanto o trabalho são fatores de produção que influenciam o crescimento do produto. Por conta disso, também foi avaliada a dependência espacial entre a taxa de crescimento do produto e os referidos fatores de produção. Para ambos os casos, a constatação é de uma autocorrelação espacial positiva e significativa, com forte concentração no espaço, dado o elevado valor do coeficiente I de Moran. Assim, conclui-se que tanto a taxa de crescimento do trabalho quanto a participação do capital no PIB possuem uma associação positiva com a taxa de crescimento econômico (Tabela 1). 
Tabela 1 - Coeficiente I de Moran - Microrregiões do Brasil

\begin{tabular}{|c|c|c|c|}
\hline \multirow{2}{*}{ Variáveis analisadas } & \multicolumn{3}{|c|}{ Convenção } \\
\hline & Rainha & Torre & 4 vizinhos \\
\hline Taxa de crescimento médio do PIB (entre 2000 e 2010) & $0,27^{\star}$ & $0,27^{*}$ & $0,28^{*}$ \\
\hline Taxa de crescimento médio das exportações (entre 2000 e 2010) & $0,09^{*}$ & $0,08^{* *}$ & $0,12^{*}$ \\
\hline Participação média do capital físico no PIB (entre 2000 e 2010) & $0,62^{*}$ & $0,62^{*}$ & $0,63^{*}$ \\
\hline Taxa de crescimento médio da população (entre 2000 e 2010) & $0,41^{*}$ & $0,41^{*}$ & $0,40^{*}$ \\
\hline $\begin{array}{l}\text { Taxa de cresc. PIB versus taxa de cresc. exportações (I Moran Bi- } \\
\text { variado) }\end{array}$ & $0,08^{\star \star}$ & $0,08^{* \star}$ & $0,09^{*}$ \\
\hline $\begin{array}{l}\text { Taxa de cresc. PIB versus participação capital físico no PIB (I Moran } \\
\text { Bivariado) }\end{array}$ & $0,28^{*}$ & $0,28^{*}$ & $0,25^{\star}$ \\
\hline $\begin{array}{l}\text { Taxa de cresc. PIB versus taxa de cresc. da população (I Moran } \\
\text { Bivariado) }\end{array}$ & $0,20^{*}$ & $0,21^{*}$ & $0,19^{*}$ \\
\hline
\end{tabular}

Fonte: Estimado pelos autores no software GeoDa, com base nos dados da pesquisa.

Nota: A pseudo-significância empírica baseada em 999 permutações aleatórias; $\left({ }^{*}\right)$ significativo a um nível de significância de $1 \% ;\left({ }^{* *}\right)$ significativo a um nível de significância de $5 \%$.

Um ponto importante a salientar é que a existência de uma autocorrelação espacial entre as variáveis faz com que seja necessária a utilização das técnicas da econometria espacial na estimação do modelo empírico. Assim, antes de reportar os resultados da estimação do modelo, realizou-se uma análise minuciosa nos resíduos, a fim de averiguar a presença de dependência espacial e, ademais, verificar qual modelo espacial é o mais adequado (Apêndice A). Partindo destes resultados, chegou-se à conclusão de que o modelo empírico deveria ser estimado pelas técnicas de painel espacial.

$\mathrm{Na}$ escolha entre o modelo de Efeitos Fixos ou o modelo de Efeitos Aleatórios, o primeiro se mostrou mais adequado aos dados e, por conta disso, apenas os resultados obtidos a partir dele serão reportados no corpo do trabalho (Tabela 2). ${ }^{8}$ Posteriormente, partiu-se para a definição de qual modelo de Efeitos Fixos é o mais adequado, observando-se dois critérios. No primeiro, os resíduos não devem apresentar autocorrelação espacial, o que não aconteceu em nenhum dos modelos estimados. Todos apresentaram dependência espacial, mas reduziram-se significativamente seus coeficientes, especialmente no modelo SAR e no SDEM (Apêndice A). O outro critério foi baseado na qualidade de ajuste do modelo conforme os critérios de

8 De acordo com o teste Hausman $(\chi 2=564,23)$, a estimativa por efeito fixo é mais apropriada que a de efeito aleatório; além do que, entre efeito fixo e MQO, a primeira é preferida $(\mathrm{F}=1,58)$. 
informação de Akaike e de Schwarz. Neste caso, o modelo $\mathrm{SAR}^{9}$ foi o que apresentou o melhor ajuste e, portanto, será utilizado como referência para a análise dos resultados (Tabela 2 - Modelo I).

Tabela 2 - Resultado da estimação do modelo de Feder (1982) com a técnica de painel de dados espacial

\begin{tabular}{|c|c|c|c|}
\hline \multirow{2}{*}{ Variável } & \multicolumn{3}{|c|}{ Modelo } \\
\hline & Efeito Fixo - SAR (I) & Efeito Fixo - SEM (II) & Efeito Fixo - SDM (III) \\
\hline $\operatorname{CRESX}_{\mathrm{jt}}\left(1-\right.$ PARTX $\left._{\mathrm{jt}}\right)$ & $\begin{array}{c}0,0019^{*} \\
(0,02)\end{array}$ & $\begin{array}{l}0,002^{*} \\
(0,01)\end{array}$ & $\begin{array}{l}0,002^{*} \\
(0,01)\end{array}$ \\
\hline CRESX $_{j \mathrm{t}} *$ PARTX $_{\mathrm{jt}}$ & $\begin{array}{l}0,00004^{*} \\
(0,0003)\end{array}$ & $\begin{array}{l}0,00004^{*} \\
(0,0003)\end{array}$ & $\begin{array}{l}0,00003^{*} \\
(0,0002)\end{array}$ \\
\hline$F T R A B_{j t}$ & $\begin{array}{c}0,012 \\
(0,118)\end{array}$ & $\begin{array}{c}0,044 \\
(0,098)\end{array}$ & $\begin{array}{c}0,079 \\
(0,053)\end{array}$ \\
\hline$I N C F_{j t}$ & $\begin{array}{l}7,742^{*} \\
(1,62)\end{array}$ & $\begin{array}{l}8,437^{*} \\
(1,82)\end{array}$ & $\begin{array}{l}8,50^{*} \\
(1,86)\end{array}$ \\
\hline $\mathrm{DC}_{\mathrm{jt}}$ & $\begin{array}{l}-1,039 \\
(0,687)\end{array}$ & $\begin{array}{l}-0,873 \\
(0,93)\end{array}$ & $\begin{array}{l}-6,09^{*} \\
(2,09)\end{array}$ \\
\hline$\lambda$ & - & $\begin{array}{l}0,337^{*} \\
(0,019)\end{array}$ & - \\
\hline$\rho$ & $\begin{array}{l}0,318^{*} \\
(0,019)\end{array}$ & - & $\begin{array}{l}0,331^{*} \\
(0,023)\end{array}$ \\
\hline $\mathrm{W} \mathrm{CRESX}_{\mathrm{jt}}\left(1-\right.$ PARTX $\left._{\mathrm{jt}}\right)$ & - & - & $\begin{array}{c}0,004^{*} \\
(0,0,002)\end{array}$ \\
\hline $\mathrm{W} \mathrm{CRESX}_{\mathrm{jt}} *$ PARTX $_{\mathrm{jt}}$ & - & - & $\begin{array}{l}-0,00001^{* *} \\
(0,00007)\end{array}$ \\
\hline $\mathrm{W} F T R A B_{j t}$ & - & - & $\begin{array}{l}-0,222 \\
(0,187)\end{array}$ \\
\hline $\mathrm{W} I N C F_{j t}$ & - & - & $\begin{array}{r}-3,914^{*} \\
(1,26)\end{array}$ \\
\hline $\mathrm{W} \mathrm{DC}$ & - & - & $\begin{array}{l}-6,50^{*} \\
(2,44)\end{array}$ \\
\hline Crit. inf. Akaike & 44457,7 & 44414,0 & 44415,7 \\
\hline Crit. Schwarz & 44491,0 & 44447,6 & 44469,4 \\
\hline
\end{tabular}

Fonte: Estimação dos autores com os dados da pesquisa.

Nota: Entre parênteses está reportado o erro padrão de Drisccoll e Kraay (1995). $I N C F_{j t}$ é o investimento em capital físico da j-ésima microrregião no tempo $t ; F T R A B_{j t}$ é a taxa de crescimento da população j-ésima microrregião no tempo $t ; C_{\text {C }} E S X_{j t}$ é a taxa de crescimento das exportações da $j$-ésima microrregião no tempo $t$; $P A R T X_{j t}$ corresponde à participação das exportações no PIB da $j$-ésima microrregião no tempo $t$; DC refere-se a uma dummy de crise ("um" para 2008, 2009 e 2010, e "zero" para os demais anos). $\left({ }^{*}\right)$ significativo a um nível de significância de 5\%; $\left({ }^{* *}\right)$ significativo a um nível de significância de $10 \%$.

9 Teste Wald igual a 73973, indicando a presença de heterocedasticidade no modelo, e o teste de Wooldridge demonstra a existência de autocorrelação serial $(19,16)$. Portanto, a especificação do modelo espacial foi modificada para acomodar ambos os problemas, utilizando o erro padrão robusto de Drisccoll e Kraay (1995). O erro padrão de Drisccoll e Kraay (1995) são robustos para os problemas de heterocedasticidade e formas gerais de dependência dos resíduos (como espacial e temporal), podendo ser aplicado em painel. 
Os principais resultados apontam que, com exceção do crescimento populacional e da dummy de crise ${ }^{10}$, todas as variáveis independentes apresentaram coeficientes estatisticamente significativos sobre a taxa de crescimento do PIB das microrregiões brasileiras. Em relação ao efeito das exportações, tanto as externalidades quanto a produtividade se mostraram relevantes e com os sinais esperados, corroborando as hipóteses centrais do modelo teórico de Feder (1982).

Os resultados mostraram que o diferencial de produtividade do setor exportador induz o crescimento econômico, corroborando a hipótese de que o setor exportador possui uma produtividade marginal dos fatores superior à do setor não exportador. A suposição é de que ao se inserir no mercado internacional, a microrregião potencializa sua eficiência produtiva, resultado do melhor aproveitamento das economias de escala e da melhor alocação dos recursos na economia (BALASSA, 1978). Neste sentido, os resultados obtidos indicam que a inserção das microrregiões brasileiras no mercado internacional promove um diferencial de suas produtividades, induzindo a dinâmica econômica local.

Além deste diferencial de produtividade, as estimativas também mostraram a existência de uma externalidade positiva do setor exportador sobre o setor não exportador; este resultado é decorrente basicamente de dois efeitos: o efeito renda e o efeito encadeamento. No caso do efeito renda, quando se exporta se gera empregos internos que podem movimentar o comércio e outras indústrias domésticas. Além disso, as ligações (linkages) que o setor exportador apresenta com outros segmentos produtivos internos promovem um efeito multiplicador na geração de renda, como também pode promover a competitividade destes segmentos, induzida pela demanda diferenciada da unidade exportadora. Portanto, não só diretamente as exportações contribuem para a formação do PIB das microrregiões do Brasil, mas também indiretamente, por meio do diferencial de produtividade e da externalidade.

\footnotetext{
${ }^{10}$ Tal variável veio com o sinal esperado (efeito negativo da crise na taxa de crescimento econômico), contudo não foi significativo. Ou seja, para os anos analisados a crise não teve um impacto significativo sobre o dinamismo econômico das microrregiões do Brasil, lembrando que, neste estudo, os anos considerados como de crise foram 2008 a 2010, podendo-se ter resultados diferentes ao considerar anos mais recentes (pós 2010).
} 
O parâmetro $\rho$ apresentou efeito positivo e significativo, demonstrando um transbordamento positivo do crescimento do PIB na dinâmica econômica das microrregiões do envoltório. Isto mostra que, quando determinada região cresce, parte desse crescimento também acaba beneficiando as microrregióes do envoltório, criando um ciclo virtuoso do crescimento.

Quanto às defasagens das variáveis explicativas do modelo SDM, a participação do capital físico no PIB apresentou significância estatística. Entretanto, o coeficiente veio com o sinal negativo, contrários ao esperado. A hipótese para tal resultado é a de que uma microrregião que tem no seu envoltório uma elevação de capital físico em relação ao seu PIB, tende a atrair capital humano para lá, em virtude dos maiores salários, bem como os próprios investimentos em capital físico, enfraquecendo o seu envoltório. Ou seja, ao invés de gerar efeitos positivos para as regiões vizinhas, a fomentação de capital físico num espaço tende a intensificar as desigualdades regionais, conforme já havia sido destacado por Myrdal (1965). Ademais, a defasagem da variável dummy de crise também apresentou significância estatística e sinal negativo. Isso evidencia que quando uma microrregião é afetada pela crise, seus efeitos tendem a ultrapassar as suas fronteiras, influenciando negativamente no desempenho econômico das microrregiões vizinhas.

Em relação ao efeito das exportações defasadas espacialmente, tanto para o diferencial de produtividade como também para as externalidades, seus resultados apresentaram significância estatística. No caso do diferencial de produtividade, seu efeito nas microrregiões vizinhas é negativo, de modo que quando se eleva o diferencial de produtividade do setor exportador de uma região tem-se, na média, um impacto negativamente no crescimento econômico do seu envoltório. Ou seja, igualmente ao obtido com a defasagem espacial da participação do capital físico no PIB, esse resultado indica que se uma microrregião consegue se destacar, detendo um setor exportador competitivo, forças centrípetas podem atrair os setores mais dinâmicos do seu envoltório, assim como a mão de obra mais qualificada, impactando negativamente no crescimento econômico das microrregiões vizinhas. 
No caso da defasagem das externalidades, seu efeito apresentou-se positivo. Neste sentido, tanto o efeito renda como também o efeito encadeamento podem ultrapassar as fronteiras, afetando as regiões do envoltório, difundindo, por exemplo, tecnologia, bem como se beneficiando de rendas obtidas com a inserção internacional da microrregião vizinha, por meio de um possível "vazamento de renda". Essas seriam algumas das formas que as externalidades de uma região afetariam o PIB de outra região. Em suma, isto significa que os efeitos indiretos das exportações sobre o crescimento econômico não ficam restritos às microrregiões exportadoras, havendo o efeito de transbordamento para as microrregiões do envoltório.

\section{Considerações finais}

Amparado na discussão acerca dos efeitos das exportações no crescimento econômico, o presente trabalho teve como objetivo verificar os efeitos das exportações no crescimento econômico das microrregiões brasileiras no período compreendido entre 2000 e 2010, à luz do modelo teórico de Feder (1982). Neste modelo, o efeito positivo das exportações sobre o crescimento deriva do diferencial de produtividade existente entre o setor exportador e não exportador, bem como pela externalidade gerada pelo setor exportador no setor não exportador.

Em termos metodológicos, o modelo econométrico foi estimado por meio da metodologia de dados em painel espacial, e as hipóteses do modelo teórico foram corroboradas. Evidenciou-se que existe um efeito indireto das exportações no crescimento econômico das microrregiões brasileiras, sendo que isso ocorre devido ao efeito transbordamento do setor exportador na competitividade dos setores não exportadores, derivado do aprimoramento da infraestrutura, da qualificação da mão de obra, bem como da própria demanda do setor exportador pelos produtos e serviços dos setores não exportadores.

De certa forma, as evidências observadas no presente trabalho podem ser preocupantes, tendo em vista que as exportações brasileiras estão concentradas, principalmente, nas regiões Sudeste e Sul. Em consequência disso, as heterogeneidades regionais podem ser ainda 
mais aprofundadas, agravando-se a distribuição da renda e da riqueza entre as microrregiões.

Nesse sentido, políticas públicas que visem à dispersão das exportações ao longo do território brasileiro são necessárias, sobretudo para as regiões Norte e Nordeste. Perobelli e Haddad (2002) destacam que a maior concentração das exportações nas regiões Sudeste e Sul ocorre devido a questões estruturais do setor produtivo, pela disponibilidade de recursos naturais, incentivos governamentais, custos inerentes ao transporte e facilidade ao mercado externo.

Partindo desta constatação, políticas públicas direcionadas à infraestrutura, como melhoramento das estradas, dos portos e aeroportos, podem contribuir para a atração de investimentos nas regiões Norte e Nordeste, para que as microrregiões aí localizadas também consigam se inserir no mercado internacional ou, ainda, aprofundar as relações comerciais já existentes. Neste caso, o argumento é o de que se o país conseguir inserir mais microrregiões no mercado internacional, o crescimento econômico pode ser maior e mais homogêneo ao longo do território brasileiro.

Destaca-se que, apesar de todo o esforço metodológico empregado na presente pesquisa, a mesma não encerra a discussão envolvendo os efeitos das exportações sobre o crescimento econômico. Algumas perguntas ainda pairam no ar como, por exemplo, será que os efeitos indiretos das exportações são os mesmos, independentemente do tipo de produto exportado? Será que os produtos com maior valor agregado causam maior externalidade na economia do que os produtos com baixa agregação de valor, como as commodities? Essas questões devem ser analisadas em trabalhos futuros. 


\section{Referências}

ALMEIRA, E. Econometria espacial aplicada. Campinas: Editora Alínea, 2012.

BALASSA, B. Exports and economic growth: further evidence. Journal of Development Economics, vol. 5, p. 181-189, 1978.

BALTAGI, B. H. Econometric Analysis of Panel Data. Chichester: John Wiley and Sons. 2005.

BREITBACH, A. C. M. Especialização e diversificação nas regiões industriais do Rio Grande do Sul. Porto Alegre: FEE, jun., 2008 (Texto para Discussão n.31).

CANTÚ, J. J. S.; MOLLIK, A, V. Efectos “Spillover" de las exportaciones en el crecimiento del producto manufacturero en las entidades federativas de México. Coloquio internacional "La mondialisation et ses effets: nouveaux débats nouvelles approches”. 2003. Disponível em: https://drjosesalazar. files.wordpress.com/2013/07/salazar-y-varella-2004.pdf. Acesso em: 09 mar. 2015.

DANOSO, V.; MARTÍN, V. Exportaciones y crecimiento económico: estudios empíricos. Instituto Complutense de Estudios Internacionales, Universidad Complutense de Madrid, Working Paper $n^{\circ} 05 / 09,2009$.

DRISCOLL, J.; KRAAY, A. Spatial correlations in panel data. The World Bank, Policy Research Working paper n. 1553, Washington, 1995.

ELHORST J. P. Specification and estimation of spatial panel data models. International Regional Science Review, v. 26, n. 3, p. 244-268. 2003.

EMERY, R. The relation of exports and economic growth. Kyklos, v. 20, p. 470-486, 1967.

FASANO FILHO, U. A expansão das exportações e o crescimento econômico: o caso do Brasil, 196984. Revista Brasileira de Economia, v. 42, nº 1, p. 73-81, jan./mar. 1988.

FEDER, G. On exports and economic growth. Journal of Development Economics, v. 12, p. 59-73, 1982.

GALIMBERTI, J.K.; CALDART, W.L. As exportações e o crescimento econômico: análise dos municípios do Corede Serra - 1997-04. Ensaios FEE, Porto Alegre, v. 31, n. 1, p. 87-112, ago. 2010.

GANI, A. Technological Achievement, High Technology Exports and Growth. Journal of Comparative International Management, v. 12, n.2, p. 31-47, 2009.

GOMES, E.C.; LIMA, R.L.; FRAGA, G.J.; PARRÉ, J.L. Exportações e PIB per capita: uma abordagem espacial utilizando a metodologia gwr. Anpec Sul, 2015. Anais... Porto Alegre, 2015

HADDAD, E. A.; PEROBELLI, F. S. Integração regional e padrão de comércio dos estados brasileiros, unidade e fragmentação: a questão regional no Brasil. Perspectiva, n. 284, p. 221-236, 2002.

HSIAO, C. Why panel data? University of Southern California, IEPR working paper n. 05.33 . 2005. Disponível em: http://papers.ssrn.com/sol3/papers.cfm?abstract_id=820204. Acessado em: 20 dez. 2014.

IBGE. Divisão do Brasil em mesorregiões e microrregiões geográficas. Rio de Janeiro, 1991.

IBRAHIM, I. On exports and economic growth. Jurnal Pengurusan, v. 21, p. 3-18, 2002.

JUNIOR, A. A. B; ALMEIDA, E. Os principais fatores internos e as exportações microrregionais brasileiras. Revista Economia Contemporânea, Rio de Janeiro, v. 13, n. 2, p. 201-227, mai/ago 2009.

KRAVIS, I. B. Trade as a handmaiden of growth: similarities between the $19^{\text {th }}$ and the $20^{\text {th }}$ centuries. Economic Journal, v. 80, n. 320, p. 850-872, Dec. 1970.

MEHDI, S.; SHAHRYAR, Z. The study examining the effect of export growth on economic growth in Iran. Business Intelligence Journal, v. 5, n. 1, p. 21-27, jan. 2012.

MICHAELY, M. Exports and growth: an empirical investigation. Journal of Developing Economics, v. 4, n. 1, p. 49-53, Mar. 1977.

MYRDAL, G. Teoria Econômica e Regiões Subdesenvolvidas. Lisboa: Editora Saga, 1965. 
PEROBELLI, F. S.; HADDAD, E. A. Padrões de comércio interestadual no Brasil, 1985 e 1997. Revista Economia Contemporânea, Rio de Janeiro, v. 10, n. 1, p. 61-88, jan./abr. 2006.

SEIJO, C. S. La relación entre el crecimiento de las exportaciones y el crecimiento económico. Revista de ciências sociales (Río Piedras), n.8, p. 170-194, 2000.

SOLOW, R. A contribution to the theory of economic growth. The Quarterly Journal of Economics, v. 70, n. 1,p.65-94, nov. 1956.

WOOLDRIDGE, J. M. Econometric analysis of cross section and panel data. Cambridge: The MIT Press, 2002.

\section{APÊNDICES}

Apêndice A - I de Moran para os resíduos

\begin{tabular}{l|c|c|c|c|c|c|c|c|c|c|c}
\hline \multicolumn{10}{c}{ Tempo } \\
\hline \multicolumn{1}{c}{ Efeito fixo } & 1 & 2 & 3 & 4 & 5 & 6 & 7 & 8 & 9 & 10 & 11 \\
\hline Sem depen. esp. & $0,20^{*}$ & $0,18^{*}$ & $0,30^{*}$ & $0,32^{*}$ & $0,38^{*}$ & $0,31^{*}$ & $0,29^{*}$ & $0,17^{*}$ & $0,24^{*}$ & $0,18^{*}$ & $0,20^{*}$ \\
SAR & $0,09^{*}$ & $0,15^{*}$ & $0,15^{*}$ & 0,05 & $0,10^{*}$ & 0,006 & $0,17^{*}$ & $-0,01$ & 0,04 & 0,06 & 0,08 \\
SEM & $0,15^{*}$ & $0,23^{*}$ & $0,23^{*}$ & $0,09^{*}$ & $0,11^{*}$ & 0,03 & $0,24^{*}$ & $-0,03$ & 0,05 & $0,11^{*}$ & $0,16^{*}$ \\
SDM & $0,08^{*}$ & $0,15^{*}$ & $0,14^{*}$ & 0,03 & $0,09^{*}$ & 0,03 & $0,19^{*}$ & $-0,01$ & 0,04 & 0,07 & $0,09^{*}$ \\
\hline
\end{tabular}

Fonte: Resultado da pesquisa.

Nota: * significativo a um nível de significância de $1 \%$. 
Apêndice B - Descrição das variáveis que integram o modelo empírico

\begin{tabular}{|c|c|}
\hline Variáveis & Descrição \\
\hline $\operatorname{CRESX}_{\mathrm{jt}}\left(1-\right.$ PARTX $\left._{\mathrm{jt}}\right)$ & $\begin{array}{l}\text { Representa a externalidade das exportações na economia. Compõe-se de } \\
\text { duas partes: a primeira refere-se ao crescimento das exportações, e; a se- } \\
\text { gunda é o percentual do PIB que não corresponde às exportaçôes (produção } \\
\text { voltada ao mercado doméstico). Ao multiplicar esses dois componentes, } \\
\text { tem-se a dinamização da economia, resultado induzido pelo crescimento das } \\
\text { exportações. Ressalta-se que os valores das exportações estavam em dó- } \\
\text { lares (site AliceWeb) e foram convertidos em reais (taxa de câmbio - efetiva } \\
\text { real - Ipeadata). }\end{array}$ \\
\hline CRESX $_{\mathrm{jt}} *$ PARTX $_{\mathrm{jt}}$ & $\begin{array}{l}\text { Refere-se à proxy utilizada para o diferencial de produtividade entre o setor } \\
\text { exportador e o setor não exportador. Tal variável é medida pela multiplica- } \\
\text { ção entre o crescimento das exportações e a participação das exportações } \\
\text { no PIB de cada microrregião. Ressalta-se que os valores das exportações } \\
\text { estavam em dólares (site AliceWeb) e foram convertidos em reais (taxa de } \\
\text { câmbio - efetiva real - Ipeadata). }\end{array}$ \\
\hline$F T R A B_{j t}$ & Representa a taxa de crescimento da população. \\
\hline$I N C F_{j t}$ & $\begin{array}{l}\text { Corresponde a participação do investimento em capital físico no PIB. Como } \\
\text { não se tem o valor de investimento em capital físico a nível de microrregião, } \\
\text { fez-se o seguinte procedimento: 1) mensurou-se o total de estabelecimentos } \\
\text { existente no país ao longo dos anos analisados e dividiu-se pelo total de } \\
\text { investimentos que o Brasil teve em cada ano, obtendo assim um valor mé- } \\
\text { dio de investimento por estabelecimento (VIE); } 2 \text { ) identificou-se o número de } \\
\text { estabelecimentos de cada microrregião, multiplicando pelo VIE; 3) Por fim, } \\
\text { dividiu-se esse valor pelo PIB, obtendo a participação do investimento em } \\
\text { capital físico no PIB de cada microrregião. Importante destacar que se fez } \\
\text { uma correlação entre o VIE e o real capital físico do país e o resultado foi de } \\
\text { uma correlação de } 0,98 \text {, demonstrando a robustez da proxy aqui utilizada. }\end{array}$ \\
\hline $\mathrm{DC}_{\mathrm{jt}}$ & $\begin{array}{l}\text { Refere-se a uma dummy de crise ("um" para } 2008,2009 \text { e 2010, e "zero" para } \\
\text { os demais anos), com o intuito de identificar o impacto que a crise teve no } \\
\text { crescimento econômico das microrregiões brasileiras. }\end{array}$ \\
\hline$\lambda$ & $\begin{array}{l}\text { Representa o coeficiente autorregressivo espacial, que capta o efeito trans- } \\
\text { bordamento na variável dependente. }\end{array}$ \\
\hline$\rho$ & $\begin{array}{l}\text { É um parâmetro autorregressivo espacial associado a defasagem do erro, } \\
\text { captando o efeito transbordamento no termo de erro. }\end{array}$ \\
\hline $\mathrm{W} \mathrm{CRESX}_{\mathrm{jt}}\left(1-\operatorname{PARTX}_{\mathrm{jt}}\right)$ & $\begin{array}{l}\text { Defasagem espacial das externalidades das exportações. Ou seja, busca } \\
\text { identificar o efeito que as externalidades das exportações das microrregiões } \\
\text { vizinhas sobre à dinâmica econômica de um município específico. }\end{array}$ \\
\hline $\mathrm{W} \mathrm{CRESX}_{\mathrm{jt}} *$ PARTX $_{\mathrm{jt}}$ & $\begin{array}{l}\text { Defasagem espacial do diferencial de produtividade entre o setor exportador } \\
\text { e o setor não exportador. Testa a existência de efeito desse diferencial para } \\
\text { o crescimento econômico das microrregiões vizinhas. }\end{array}$ \\
\hline $\mathrm{W} \mathrm{FTRAB}_{j t}$ & Defasagem espacial do crescimento populacional. \\
\hline $\mathrm{W}_{I N C F_{j t}}$ & $\begin{array}{l}\text { Refere-se à defasagem espacial da participação do investimento em capital } \\
\text { físico no PIB. }\end{array}$ \\
\hline $\mathrm{W} \mathrm{DC}_{\mathrm{jt}}$ & Defasagem espacial da dummy de crise. \\
\hline
\end{tabular}

